\title{
THE
}

\section{Multiple environmental chemical exposures to lead, mercury and polychlorinated biphenyls among childbearing-aged women (NHANES 1999-2004): Body burden and risk factors}

\author{
Marcella Remer Thompson \\ University of Rhode Island \\ Kim Boekelheide
}

Follow this and additional works at: https://digitalcommons.uri.edu/nursing_facpubs

This is a pre-publication author manuscript of the final, published article.

Creative Commons License

(c) $(7) \Theta$

This work is licensed under a Creative Commons Attribution-Noncommercial-No Derivative Works 4.0 License.

\section{Citation/Publisher Attribution}

Remer Thompson, M., \& Boekelheide, K. (2013). Multiple environmental chemical exposures to lead, mercury and polychlorinated biphenyls among childbearing-aged women (NHANES 1999-2004): Body burden and risk factors. Environmental Research, 121, 23-30. doi: 10.1016/j.envres.2012.10.005 Available at: https://doi.org/10.1016/j.envres.2012.10.005

This Article is brought to you for free and open access by the College of Nursing at DigitalCommons@URI. It has been accepted for inclusion in College of Nursing Faculty Publications by an authorized administrator of DigitalCommons@URI. For more information, please contact digitalcommons-group@uri.edu. 


\title{
Multiple environmental chemical exposures to lead, mercury and polychlorinated biphenyls among childbearing-aged women (NHANES 1999-2004): Body burden and risk factors
}

\author{
Marcella Remer Thompson ${ }^{a, b,{ }^{*}}$ and Kim Boekelheide ${ }^{a}$ \\ aSuperfund Research Program, Brown University, Providence, Rhode Island, USA \\ ${ }^{b}$ College of Nursing, University of Rhode Island, Kingston, Rhode Island, USA
}

\begin{abstract}
Background-Lead, mercury and polychlorinated biphenyls (PCBs) are neurotoxicants with intergenerational health consequences from maternal body burden and gestational exposures. Little is known about multiple chemical exposures among childbearing-aged women.
\end{abstract}

Objectives-To determine the percentage of women aged 16-49 of diverse races and ethnicities whose body burdens for all three xenobiotics were at or above the median; to identify mixed exposures; and to describe those women disproportionately burdened by two or more of these chemicals based on susceptibility- and exposure-related attributes, socioeconomic factors and race-ethnicity.

Methods-Secondary data analysis of National Health and Nutrition Examination Survey (19992004).

Results-The best-fit logistic regression model without interactions contained 12 variables. Four risk factors associated with body burden were notable $(P \leq 0.05)$. An exponential relationship was demonstrated with increasing age. Any fish consumption in past 30 days more than doubled the odds. Heavy alcohol consumption increased the relative risk. History of breastfeeding reduced this risk. These women were more likely to have two xenobiotics at or above the median than one.

More than one-fifth of these childbearing-aged women had three xenobiotic levels at or above the median.

Conclusions-These findings are among the first description of US childbearing-aged women's body burden and risk factors for multiple chemical exposures. This study supports increasing age, any fish consumption and heavy alcohol consumption as significant risk factors for body burden. History of breastfeeding lowered the body burden. Limited evidence was found of increased risk among minority women independent of other risk factors.

\section{Keywords}

Childbearing-aged women; NHANES; Lead; Mercury; PCBs

(C) 2012 Elsevier Inc. All rights reserved.

"Corresponding author at: Brown University, 70 Ship Street, Box G-E5, Providence, Rhode Island 02912, USA. Fax: +1 401863 9008. Marcella_Thompson@brown.edu (M.R. Thompson).

Human subjects research

The University of Rhode Island Institutional Review Board Chair determined that this secondary analysis of free and publicly available data was not human subjects' research. 


\section{Introduction}

Lead, mercury, and polychlorinated biphenyls (PCBs) are each known to have neurobehavioral and neurodevelopmental consequences in animal models and human populations. Despite what is known about the neurotoxicity from exposure to these environmental chemicals individually, the health effects from co-exposure to these chemicals and the corresponding biologically effective dose are relatively unknown. There is a need to assess these chemicals' cumulative risk for neurotoxicity, even though they do not have the same mode of action (National Research Council, 2008).

Findings from in vivo and in vitro mechanistic studies of binary combinations of the chemicals of interest are contradictory (Radio et al., 2010). These contradictions are likely due to differences among the mechanisms studied, outcomes evaluated, and variability in tissue-, time- and dose-dependent bioaccumulation (Meacham et al., 2005). For example, Bemis and Seegal (1999) found dopamine concentrations were significantly decreased $(P \leq$ $0.001)$ in the brains of adult rats exposed to PCBs (1:1 mixture of Aroclor $\left.{ }^{\mathrm{TM}} 1254 / 1260\right)$ and methyl mercury as compared to either chemical alone. The observed values were $20 \%-50 \%$ lower than predicted values, suggesting a synergistic effect that the researchers attributed to a common site of action involving intracellular calcium regulation in neural cells. Other in vitro and in vivo mechanistic studies examining different endpoints have found varying effects from antagonistic (Sitarek and Gralewicz, 2009) to non-additive (Coccini et al., 2006) to additive (Costa et al., 2007; Roegge et al., 2004). Goldoni et al. (2008) found asynchronous exposure produced antagonism when methyl mercury preceded PCB 153 and additivity when PCB 153 preceded methyl mercury. These mechanistic studies have provided some insights into the nature of these binary chemical interactions; however, they do not elucidate the human exposure conditions under which interactions are likely to occur.

The body burden from past exposures to these chemicals, as well as those maternal exposures that occur during gestation can transfer to the fetus via the placenta, and to infant and child during lactation. These effects are well documented and have been reviewed elsewhere (Wigle et al., 2007). Because body burden potentially affects the neurological development of the next generation, childbearing-aged women in general - not just those who are currently pregnant - are of special public health concern. While these neurotoxicants are known to be pervasive and persistent environmental contaminants, little is known about the prevalence of co-exposures to these chemicals among childbearing-aged women (Denham et al., 2005; Qin et al., 2010).

Bioavailability is dependent upon the distribution, bioaccumulation, storage and elimination capabilities and capacities of the human body (National Research Council, 2006). Woodruff et al. (2011) reported 89\%-100\% of pregnant and non-pregnant women in the United States have detectable levels of at least one of these xenobiotics (i.e., lead, mercury, PCBs). There is a need to characterize body burdens to these three neurotoxicants among childbearingaged women.

The health impact of exposures to multiple environmental chemicals may be magnified even more among vulnerable population subgroups. For example, these childbearing-aged women could share susceptibility- and exposure-related attributes, socioeconomic factors and raceethnicity. Susceptibility-related attributes (reproductive status, health status and nutritional status) modify the biological response to exposure. Exposure-related attributes (acculturation, dietary consumption, alcohol consumption, tobacco use, residential characteristics and occupation) increase the likelihood of exposure to environmental contaminants. Socioeconomic factors (education, employment, income and marital status) and race-ethnicity influence health indirectly through complex interactions with 
susceptibility- or exposure-related attributes or both (Sexton et al., 1993). (See Fig. 1). There is a paucity of information about subgroups of childbearing-aged women who may be disproportionately exposed and/or impacted by co-exposures to these three neurotoxicants.

\subsection{Research questions}

The aim of this research was to characterize the body burden and covariates for exposure to three neurotoxicants among childbearing-aged women living in the US 1999 through 2004. There were three research questions:

1. What was the percentage of childbearing-aged women who had body burdens at or above the median for lead, mercury and polychlorinated biphenyls (PCBs)?

2. What was the extent of their mixed exposures?

3. What, if any, subsets of these women were disproportionately burdened by two or more of these environmental chemicals based on susceptibility-related attributes, exposure-related attributes, socioeconomic factors, and race-ethnicity?

\section{Materials and methods}

\subsection{Description of dataset}

This study analyzed data from the National Health and Nutrition Examination Survey (NHANES), a national probability sample (1999-2004). All NHANES protocols were approved by the Centers for Disease Control and Prevention, National Center for Health Statistics Research Ethics Review Board (Centers for Disease Control and Prevention, 2010). There was a purposeful oversampling of select subgroups: adolescents, the elderly, non-Hispanic blacks, Mexican Americans and low-income non-Hispanic whites. Oversampling increased the reliability and precision of health status indicator estimates for these subgroups. To compensate for these selection biases, NHANES assigned a sample weight to each person based on US census data for gender, age and race-ethnicity (Centers for Disease Control and Prevention, 2009a, 2009b). For this study, a six-year weighting variable was created per analytical guidelines (Centers for Disease Control and Prevention, 2006). Using these adjusted (weighted) data allowed for estimation of true variance and generalizability to the US population (Centers for Disease Control and Prevention, n.d.).

\subsection{Study population}

The study population consisted of childbearing-aged females aged 16-49 of diverse races and ethnicities who were living in the US from 1999 to 2004. The outcome of interest was based on the presence of three xenobiotics: lead, total mercury (organic mercury plus inorganic mercury) in blood and PCBs (measured as the summed value of four lipidadjusted congeners $118,138 / 158,153$ and 180) in serum of these women. For this study, participants were required to have all laboratory tests that identified these three variables of interest, and deemed by interviewers to have reliable dietary recall. Using these inclusion criteria, $14.4 \%$ of subjects were dropped from the original laboratory sample. The final study sample consisted of 3173 women who represented 134,502,033 women when data were weighted to the US population (Supplemental Material Table 1).

\subsection{Data analyses}

Procedures for sample collection, laboratory methods and analytic analyses are described elsewhere (Centers for Disease Control and Prevention, 2009a, 2009b). The level of detection (LoD) for each PCB congener varied as each sample from each individual had its own limit; the larger the volume of a sample, the lower the detection limit. NHANES noted whether PCB values were above or below the limit of detection. Lower limits of detection 
were identified for lead and total mercury. For these two xenobiotics, values below the LoD were imputed (LoD divided by the square root of two) by NHANES. There were no missing data. For each sample, lipid-adjusted PCB congeners 118, 138/158, 153 and 180 were summed to create a new variable, the sum of lipid-adjusted PCBs in accordance with Schisterman et al. (2005). As a result, true total PCB exposure may be underestimated somewhat (Longnecker et al. 2003).

Total mercury was used in this study rather than speciated organic and inorganic mercury (Cernichiari et al., 1995). Prior research has assumed methyl mercury and organic mercury levels in blood to be synonymous since ethyl-, phenyl- and methoxyethyl-mercury are converted rapidly to inorganic mercury (Björnberg, et al., 2005; Mahaffey et al., 2009). Elemental mercury is converted also, albeit more slowly. The median value for inorganic mercury was found in this cohort to be less than its lower detection level.

Data analysis began with concatenating and organizing the dataset, operationalizing dependent and independent variables and constructing software instructions in 64-bit SAS ${ }^{\odot}$ and SAS-callable SUDAAN ${ }^{\odot}$.

Descriptive statistics for specific xenobiotic levels in childbearing-aged women can be found in Supplemental Material Table 2. Since values at +3 SD were of greatest concern, all xenobiotic values were included in the analyses. Each dependent variable was dichotomized using the median as the cut point. The median for lead, total mercury and the sum of PCBs was equivalent to $0.89 \mu \mathrm{g} / \mathrm{dL}, 0.99 \mu \mathrm{g} / \mathrm{L}$ and $51.59 \mathrm{ng} / \mathrm{g}$ (lipid), respectively. The clinical significance of these values is not known. It is conceivable that the dose threshold for adverse health effects from a combination of these chemicals may be lower and the health effects more severe than those known to be associated with exposure to any individual chemical (Schmidt, 2006).

For research question one, a composite dependent variable was created with four categories: 0 (no xenobiotic levels at or above the median); 1 (one of three xenobiotic level at or above the median); 2 (two of three xenobiotic levels at or above the median); and 3 (three xenobiotic levels at or above the median). For research question two, a different dependent variable was created using only two categories to assure adequate cell sizes and improve statistical reliability: 1 (no or one xenobiotic level at or above the median) versus 2 (two or three xenobiotic levels at or above the median).

Informed by a review of the scientific literature, NHANES was scrutinized to identify appropriate measures of susceptibility and exposure-related attributes, socioeconomic factors and race-ethnicity. Not all known risk factors could be operationalized given the data available. Variable frequencies were assessed for each of the independent variables to assure adequate numbers met the NHANES guidelines for statistical reliability (Centers for Disease Control and Prevention, 2006). "Don't know" and "refused" answers were recorded as "missing". Missing values were addressed on a variable-by-variable basis.

Bivariate analyses $\left(\chi^{2}\right)$ were conducted on selected pairs of independent variables. Subsequently, some operational definitions were refined. Differences in participation by season $(P=0.40)$, time of day for data collection $(P=0.18)$, fasting time $(P=0.63)$ or usual/ unusual food consumption $(P=0.51)$ were not correlated with the dichotomous dependent variable. The large sample size compensated for intra-individual variability associated with intermittent exposures (Needham et al., 2005).

For research question one, crude prevalence estimates for each specific environmental chemical were derived by dividing the number of childbearing-aged women at or above the median by the total population of childbearing-aged women using data weighted to the US 
population. These crude prevalence estimates are reported as percentages in Fig. 2. Data were sorted by stratum and masked variance unit variables to avoid biased estimates (Centers for Disease Control and Prevention, 2006). Estimates of sampling errors were calculated by the Taylor series linearization method with replacement. Bivariate analyses $\left(\chi^{2}\right)$ identified the most common binary chemical combinations with the outcome in two categories.

For research question two, bivariate analyses $\left(\chi^{2}\right)$ of covariates on outcome with two categories were performed with adjusted (weighted) data. Using all covariates related to the outcome at $P \leq 0.20$, a multivariate logistic regression model was developed by creating a series of nested models and utilizing likelihood ratio testing. All tests for collinearity among the independent variables were negative. Odds ratios (OR) were calculated with corresponding $95 \%$ confidence intervals (CI) as estimates of risk for each factor using the best-fit logistic regression model with no interactions. Two-way interactions among the independent variables were tested by comparing nested models using likelihood ratio testing. Overparameterization occurred after two sequential nested model operations due to small individual cell size. Rather than introduce prejudice to the model, all two-way interactions were identified (Supplemental Material Table 3).

\section{Results}

The final cohort for this study consisted of 3173 women who met all inclusion criteria. These women represented 134.5 million women when generalized to the US population. $14 \%$ of childbearing-aged women were $16-19$ years old, $34 \%$ were ages $20-29,27 \%$ were 30-39 years old, and 25\% were ages $40-49$. 73\% were non-Hispanic white, $10 \%$ nonHispanic black, 6\% Mexican American, 6\% other Hispanics (12\% All Hispanics) and 5\% were Asian, Pacific Islander, Native American or multi-racial (Supplemental Material Table $1)$.

\subsection{Research question one and two}

More than one-fifth of childbearing-aged women had xenobiotic levels at or above the median for all three chemicals. Among the $33 \%$ of women who had two xenobiotic levels at or above the median, it was as likely to be PCBs-lead (36\%), mercury-lead (34\%) or mercury-PCBs (29\%). Among the $27 \%$ of women having only one xenobiotic level at or above the median, it was as likely to be lead (43\%), mercury (36\%) or PCBs (21\%). Seventeen percent of childbearing-aged women had no xenobiotic levels at or above the median (Fig. 2).

\subsection{Research question three}

For the best-fit logistic regression model, body burden was defined as having two or more xenobiotic levels at or above the median. This model had 12 variables: age, fish consumption, alcohol consumption, history of breastfeeding, household size, highest education level attained, shellfish consumption, language spoken at home, race-ethnicity, selenium intake/RDA, currently breastfeeding and employment status (Table 1). Interactions were not included because of overparameterization. Goodness-of-fit was fair $\left(R^{2}=0.25\right)$. There were four statistically significant findings $(P \leq 0.05)$ regarding relative risk for higher body burden involving age, fish consumption, alcohol consumption, and history of breastfeeding.

The odds of having two or more xenobiotic levels at or above the median rose exponentially with age $(P<0.001)$. For women aged $40-49$, their odds were 30 times higher than odds for women aged 16-19 (Fig. 3). 
Consuming fish more than once per week quadrupled the odds of having two or more xenobiotic levels at or above the median $(P<0.001)$ when compared to those women who had no fish consumption during this same time period [OR=4.50; 95\% CI, 2.49-8.12]. Fish consumption correlated significantly to mercury- $\mathrm{PCB}$ exposures $(\mathrm{P}<0.001)$.

Heavy alcohol consumption and/or binge drinking raised the odds of having two or more xenobiotic levels at or above the median $(P \leq 0.03)$ when compared to those women who had never or seldom drank alcohol during this same time period [OR=1.56; 95\% CI, $0.81-$ 3.01].

Those women who had breastfed at least one child for one month or more were $44 \%$ less likely [OR $=0.56 ; 95 \%$ CI $0.33-0.94$ ] to have two or more xenobiotic levels at or above the median than those who had never breastfed $(P \leq 0.03)$.

While retained as an important parameter in the model, race-ethnicity was not statistically significant, independent of other risk factors $(P \leq 0.22)$. Regardless, the odds of having two or more xenobiotic levels at or above the median trended higher among non-Hispanic blacks [OR=1.55; 95\% CI 1.00-2.38], Hispanics [OR=1.28; 95\% CI 0.63-2.60], and Asian, Pacific Islander, Native American or multi-racial women [OR=1.57; 95\% CI 0.41-6.08] than that of non-Hispanic whites.

\section{Discussion}

The aim of this research was to characterize the body burden and covariates for exposure to three neurotoxicants among childbearing-aged women living in the US from 1999 through 2004. The magnitude of exposure to multiple environmental chemicals is underscored by the observation reported here that $23 \%$ of childbearing-aged women had three and another $33 \%$ had two xenobiotic levels at or above the median, where one would expect $12.5 \%$ and $25 \%$, respectively. These findings support the need for health outcomes research resulting from co-exposures to all three neurotoxicants.

Lead-PCBs were identified as a common binary combination among childbearing-aged women who had two xenobiotic levels at or above the median. In their study of 138 adolescent Akwesasne (Mohawk) girls, Denham et al. (2005) found a statistically significant interaction between lead, four estrogenic PCB congeners $(52,70,101 / 90,187)$ and the delayed attainment of menses $(P<0.05)$; this relationship was nonlinear. Few studies have examined this binary combination (Boucher et al., 2012; Stewart et al., 2006). Mechanistic studies are needed to describe the joint toxic action of this particular binary chemical combination.

The odds of having two or more xenobiotic levels at or above the median rose exponentially with age. This study confirmed previously reported findings of a strong correlation between age with PCBs (Axelrad et al., 2009), lead (Mushak, 1998) and methyl mercury (Caldwell et al., 2009). This study's oldest cohort of women (aged 40-49) had a markedly higher risk [OR=29.81; 95\% CI 7.66-115.99]. While five US studies have examined blood for lipidadjusted levels of PCB congeners $(118,138,153,180)$ in older women (Laden et al., 2001), data correlating xenobiotic levels with age by decade were not available for comparison. In this study, the women aged 40-49 were born between 1950 and 1963 when pollution levels were significantly higher than current levels. If historic emissions are a valid explanation, some women older than 49 may have equally high or higher xenobiotic levels. Their coexposures and the potential relationship to neurodegenerative disease among this age cohort should be examined. 
Consuming any fish in the prior 30 days was associated with having two or more xenobiotic levels at or above the median. Domestic and imported sea food and freshwater fish consumption are significant predictors of adult methyl mercury and PCB levels (Grandjean et al., 1992; Gunderson, 1995) and to a lesser extent, lead (Falco et al., 2006). Since the halflives of mercury in blood and PCBs in serum are approximately 70 days, the 30-day recall reflects xenobiotic levels more appropriately than 24-hour recall (Tran et al., 2004). Individual cell size was too small to analyze individual consumption data on predatory species (i.e., shark, swordfish or mackerel) known to biomagnify methyl mercury and PCBs. Consuming tuna, salmon or haddock was significantly related $(P<0.05)$ to higher body burden. Relative risk quadrupled when these fish were consumed more than once per week (Fig. 4).

These findings support reducing environmental chemical exposures associated with fish consumption. Though the US Food and Drug Administration (2011) recommended a tolerance level for methyl mercury of 1 and $2 \mu \mathrm{g} / \mathrm{g}$ for PCBs in edible fish entering interstate commerce, this recommendation is neither legally enforceable nor applicable to intrastate commerce, recreational, or subsistence fishing. A nutrition rating system for fish at pointsof-sale would increase awareness among consumers. "Food labels should give clear guidance about their healthfulness and encourage healthier choices through simplicity, visual clarity, and the ability to convey meaning without written information" (Institute ofMedicine (IOM), 2011), p. 1).

While heavy alcohol consumption and binge drinking appeared to increase the odds of having two or more xenobiotic levels at or above the median, moderate alcohol consumption tended to decrease these odds slightly but not significantly when compared to non- and seldom drinkers. While alcohol consumption has been associated with reduced cardiovascular disease risk (Brien et al., 2011), no evidence exists of a similar effect on xenobiotic body burden. Alcohol potentiation of prenatal methyl mercury- and lead-related toxicities has been demonstrated in animal studies (Gupta and Gill, 2000; Maia et al., 2009). Gender-based alcohol studies show greater severity of alcohol-related neurological damage among women than men (Mancinelli et al., 2009). In this study, all 16-19 year olds were categorized as non- and seldom drinkers because NHANES restricted these data. Fryar et al. (2009) estimated as many as $18.5 \%$ females aged 16-17 are heavy alcohol consumers or binge drinkers. Comparatively, in this study, $19 \%$ of this age cohort had serum cotinine levels $>10 \mu \mathrm{g} / \mathrm{dL}$ indicating they were active smokers. Misclassification may have underestimated the true prevalence of alcohol consumption among the youngest cohort of women and contributed to the overall instability in this relationship between alcohol and body burden (Shrader-Frechette, 2008).

A history of breastfeeding at least one child for one month or more was inversely correlated with increased body burden [OR=0.56; 95\% CI 0.33-0.94]. Conversely, current breastfeeding tended to increase the odds of these women having two or more xenobiotics at or above the median, however this relationship was not significant [OR=1.97; 95\% CI 0.566.89]. All three xenobiotics have been measured in breast milk (Agency for Toxic Substances and Disease Registry (ATSDR), 2004; Gundacker et al., 2002). These findings suggest breastfeeding increases chemical exposures for infants and children while reducing total maternal body burden with a potentially lasting effect.

Like fish consumption, there should be a balanced approach to communicating the risks and benefits of breastfeeding. There is ample scientific evidence for health advantages associated with breastfeeding (Arendt, 2008). Conversely, there is ample scientific evidence that xenobiotic milk concentrations reflect the nursing infant's exposure (Needham et al., 2011) and learning and developmental effects occur at blood levels as low as $2 \mu \mathrm{g} / \mathrm{dL}$ for 
lead (Collaborative on Health and the Environment's Learning and Developmental Disabilities Initiative, 2008). Currently, the Centers for Disease Control and Prevention National Center for Environmental Health (2010) recommends women with higher than 40 $\mu \mathrm{g} / \mathrm{dL}$ blood lead levels to pump and discard their breast milk until their blood levels are lowered. There are no similar recommendations for mercury or PCBs.

As stated previously, environmental chemicals addressed in this study are known to transfer from maternal blood through the placenta to the fetus (Needham et al., 2011). Woodruff et al. (2011) found xenobiotic levels in pregnant women were higher than non-pregnant women when levels were adjusted for covariates (i.e., age, race-ethnicity, education, marital status, parity, body mass index and smoking). Multiple chemical exposures among pregnant women should be described more fully and compared to non-pregnant women.

As an estimate of risk, race-ethnicity was not statistically significant in this study, but there were differences observed. Health disparities among racial and ethnic minorities are well known (Morello-Frosch and Shenassa, 2006; Payne-Sturges and Gee, 2006). The odds of minority women having two or more of these xenobiotics at or above the median were higher than for non-Hispanic whites (Table 1). This study used data weighted to the US population dominated by non-Hispanic whites $(73 \%)$. Since race and ethnicity are social and not biological constructs, this "bioethnic conscription" may act as an indirect surrogate for socioeconomic disadvantage (Montoya, 2007). However, neither three socioeconomic indicators (food security, time in longest employment and marital status) nor any of the categorical income variables factored into the model $(P>0.20)$. In the absence of bias and real effect, the effect of race-ethnicity may be a random variation. Examining these data for each racial-ethnic group would allow for a more detailed comparison.

The findings of this study should be used to inform healthcare practitioners and environmental health professionals of the wide-spread prevalence of childbearing-aged women's exposure to lead, mercury and PCBs. Emphasis should be placed on bioaccumulation, maternal exposures and intergenerational transfers during gestation and lactation. Longitudinal prospective studies should focus on the long-term health impacts of bioaccumulation from multiple environmental chemical exposures. Prospective studies spanning more than two generations should examine transgenerational consequences of these exposures.

\subsection{Study limitations}

The goodness-of-fit for the logistic regression model without interactions was fair $\left(R^{2}\right.$ $=0.25$ ). A coefficient of determination less than 0.40 is not uncommon with cross-sectional studies (Lehmann, 1975; Murray, 2005). To improve this metric, interaction among independent variables could be more fully described within the model. Adding to the dataset (i.e., NHANES 2005-2010) would sustain adequate cell counts required for sequential nested model operations; $33 \%$ of two-way interactions were strongly significant $(P<0.001)$. Comparing this study's best-fit logistic regression model to similar models for each individual chemical as well as models for binary chemical combinations could lead to a better understanding of exposure covariates. Aside from data adequacy, the body burden does not identify sources of exposure. Bioaccumulation and intergenerational transfers complicate this identification. Overall, there is a limit to understanding these complex relationships using cross-sectional studies.

This study examined three chemicals—only a fraction of all chemicals detected in the environment and in humans. No inference should be made with regard to exposures to other chemicals. Only associations could be made about the relationships between dependent and independent variables since all data were collected at a single point in time. While these 
findings can be generalized to the population of childbearing-aged women who lived in the United States 1999-2004, no inferences should be made about exposures among other populations inside or outside the United States, nor should the results be extrapolated in terms of exposure risk for any given individual.

In conclusion, these findings are among the first description of body burden and risk factors for multiple chemical exposures among US childbearing-aged women. This study further supports increasing age, any fish consumption, and heavy alcohol consumption as significant risk factors for body burden. Prior history of breastfeeding lowered the body burden. Limited evidence was found of increased risk of exposure for minority status independent of other risk factors.

\section{Supplementary Material}

Refer to Web version on PubMed Central for supplementary material.

\section{Acknowledgments}

The research described was supported by Award Number P42-ES013660 from the National Institute of Environmental Health Sciences, The Graduate School of the University of Rhode Island and Sigma Theta Tau (International Nursing Honor Society) Delta Upsilon Chapter-At-Large. The content is solely the responsibility of the authors and does not necessarily represent the official views of the National Institute of Environmental Health Sciences or the National Institutes of Health. These funding sources had no role in the design or analysis of the study publication. K. Boekelheide is an occasional expert consultant for chemical and pharmaceutical companies.

\section{Abbreviations}

$\begin{array}{ll}\text { IHg } & \text { Inorganic mercury } \\ \text { LoD } & \text { Level of detection } \\ \text { MeHg } & \text { Methyl mercury } \\ \text { n.d } & \text { No date } \\ \text { Pb } & \text { Lead } \\ \text { PCBs } & \text { Polychlorinated biphenyls } \\ \text { RDA } & \text { Recommended daily allowance } \\ \text { RfD } & \text { Reference dose } \\ \text { THg } & \text { Total mercury }\end{array}$

\section{References}

Agency for Toxic Substances and Disease Registry (ATSDR). Interaction Profile for Persistent Chemicals Found in Breast Milk (Chlorinated Dibenzo-p-Dioxins, Hexachlorobenzene, p,p'-DDE, Methylmercury, and Polychlorinated Biphenyls). Author; Atlanta, GA: 2004.

Arendt M. Communicating human biomonitoring results to ensure policy coherence with public health recommendations: analyzing breast milk while protecting, promoting and supporting breastfeeding. Environ Health. 2008; 7:S6. [PubMed: 18541072]

Axelrad DA, Goodman S, Woodruff T. PCB body burden in U.S. women of childbearing age 20012002: an evaluation of alternate summary metrics of NHANES data. Environ Res. 2009; 109:368378. http://dx.doi.org/10.1016/j.envres.2009.01.003. [PubMed: 19251256]

Bemis JC, Seegal RF. Polychlorinated biphenyls and methylmercury act synergistically to reduce rat brain dopamine content in vitro. Environ Health Perspect. 1999; 107:879-885. [PubMed: 10544155] 
Björnberg KA, Vahter M, Berglund B, Niklasson B, Blennow M, Sandborgh-Englund G. Transport of methylmercury and inorganic mercury to the fetus and breast-fed infant. Environ Health Perspect. 2005; 113:1381-1385. [PubMed: 16203251]

Boucher O, Burden MJ, Muckle G, Saint-Amour D, Ayotte P, Dewailly E, Nelson CA, Jacobson SW, Jacobson JL. Response inhibition and error monitoring during a visual go/no-go task in Inuit children exposed to lead, polychlorinated biphenyls, and methylmercury. Environ Health Perspect. 2012; 120(4):608-615. http://dx.doi.org/10.1289/ehp.1103828. [PubMed: 22142904]

Brien SE, Ronksley PE, Turner BJ, Mukamal KJ, Ghali WA. Effect of alcohol consumption on biological markers associated with risk of coronary heart disease: systematic review and metaanalysis of interventional studies. BMJ (Clinical Research ed). 2011; 342:636. http://dx.doi.org/ 10.1136/bmj.d636.

Caldwell KL, Mortensen ME, Jones RL, Caudill SP, Osterloh JD. Total blood mercury concentrations in the US population: 1999-2006. Int J Hyg Environ Health. 2009; 212:588-598. http://dx.doi.org/ 10.1016/j.ijheh.2009.04.004. [PubMed: 19481974]

Centers for Disease Control and Prevention. [accessed 06.04.12] National Center for Health Statistics. Analytic and Reporting Guidelines. 2006. Available from: 〈http://www.cdc.gov/nchs/nhanes/ nhanes2003-2004/analytical_guidelines.htm〉

Centers for Disease Control and Prevention; National Center for Environmental Health. [accessed 06.04.12] Fourth National Report on Human Exposure to Environmental Chemicals. 2009a. Available from: 〈http://www.cdc.gov/exposurereport/〉

Centers for Disease Control and Prevention. [accessed 06.04.12] National Center for Health Statistics. Web Tutorial. 2009b. Available from: 〈http://www.cdc.gov/nchs/tutorials/NHANES/ index_current.htm $\rangle$

Centers for Disease Control and Prevention; National Center for Health Statistics. [accessed 06.04.12] NCHS Research Ethics Review Board (ERB) Approval. 2010. Available from: 〈http:// www.cdc.gov/nchs/nhanes/irba98.htm

Centers for Disease Control and Prevention; National Center for Health Statistics. [accessed 06.04.12] Population Information: Bridged Race Estimates. n.d. Available from: 〈http://wonder.cdc.gov〉

Cernichiari E, Toribara TY, Liang L, Marsh DO, Berlin MW, Myers GJ, Cox C, Shamlaye CF, Choisy O, Davidson P, Clarkson TW. The biological monitoring of mercury in the Seychelles study. Neurotoxicology. 1995; 16:613-628. [PubMed: 8714867]

Coccini T, Randine G, Castoldi A, Grandjean P, Ostendorp G, Heinzow B, Manzo L. Effects of developmental co-exposure to methyl mercury and $2,2^{\prime}, 4,4^{\prime}, 5,5^{\prime}$-hexachlorobiphenyl (PCB153) on cholinergic muscarinic receptors in rat brain. Neurotoxicology. 2006; 27:468-477. http:// dx.doi.org/10.1016/j.neuro.2005.12.004. [PubMed: 16455139]

Collaborative on Health and the Environment's Learning and Developmental Disabilities Initiative. [accessed 06.04.12] Policy Implications Based on the Scientific Consensus Statement on Environmental Agents Associated With Neurodevelopmental Disorders. 2008. Available from: 〈http://www.iceh.org/pdfs/LDDI/LDDIStatement.pdf〉

Costa L, Fattori V, Giordano G, Vitalone A. An in vitro approach to assess the toxicity of certain food contaminants: methyl mercury and polychlorinated biphenyls. Toxicology. 2007; 237:65-76. http://dx.doi.org/10.1016/j.tox.2007.05.003. [PubMed: 17553607]

Denham M, Schell LM, Deane G, Gallo MV, Ravenscroft J, DeCaprio AP. Relationship of lead, mercury, mirex, dichlorodiphenyldichloroethylene, hexachlorobenzene and polychlorinated biphenyls to timing of menarche among Akwesasne Mohawk girls. Pediatrics. 2005; 115:27-34. http://dx.doi.org/10.1542/peds.2004-1161.

Falco G, Llobet JM, Bocio A, Domingo JL. Daily intake of arsenic, cadmium, mercury and lead by consumption of edible marine species. J Agric Food Chem. 2006; 54(16):6106-6112. http:// dx.doi.org/10.1021/jf0610110. [PubMed: 16881724]

Fryar C, Merinom M, Hirsch R, Porter K. Smoking, Alcohol Use and Illicit Drug Use Reported by Adolescents Aged 12 to 17 years: United States, 1999-2004. National Health Statistics Reports. 2009; 15:1-28. [PubMed: 19634304]

Goldoni M, Caglieri A, Poli D, Vettori M, Ceccatelli S, Mutti A. Methylmercury at low doses modulates the toxicity of PCB153 on PC12 neuronal cell line in asynchronous combination 
experiments. Food Chem Toxicol. 2008; 46:808-811. http://dx.doi.org/10.1016/j.fct.2007.09.104. [PubMed: 17980472]

Grandjean P, Weihe P, Jorgensen PJ, Clarkson T, Cernichiari E, Videro T. Impact of maternal seafood diet on fetal exposure to mercury, selenium and lead. Arch Environ Health. 1992; 47:185-195. [PubMed: 1596101]

Gundacker C, Pietschnig B, Wittmann KJ, Lischka A, Salzer H, Hohenauer L, Schuster E. Lead and mercury in breast milk. Pediatrics. 2002; 110:873-878. [PubMed: 12415023]

Gunderson EL. Dietary Intakes of Pesticides, Selected Elements, and Other Chemicals: FDA Total Diet Study, June 1984-April 1986. J AOAC Int. 1995; 78:910-921. [PubMed: 7580329]

Gupta V, Gill KD. Influence of ethanol on lead distribution and biochemical changes in rats exposed to lead. Alcohol. 2000; 20:9-17. http://dx.doi.org/10.1016/S0741-8329(99)00046-4. [PubMed: 10680712]

Institute of Medicine (IOM). [accessed 06.04.12] Front-of-Package Nutrition Rating Systems and Symbols: Promoting Healthier Choices. 2011. Available from: 〈http://www.iom.edu/Reports/ 2010/Examination-of-Front-of-Package-Nutrition-Rating-Systems-and-Symbols-Phase-1Report.aspx $\rangle$

Laden F, Collman G, Iwamoto K, Alberg A, Berkowitz G, Freudenheim J, Hankinson SE, Helzlsouer KJ, Holford TR, Huang HY, Moysich KB, Tessari JD, Wolff MS, Zheng T, Hunter DJ. 1,1dichloro-2,2-bis (p-chlorophenyl)ethylene and polychlorinated biphenyls and breast cancer: combined analysis of five US studies. J Natl Cancer Inst. 2001; 93:768-776. [PubMed: 11353787]

Lehmann DR. Validity and goodness-of-fit in data analysis. Adv Consum Res. 1975; 2:741-750.

Longnecker MP, Wolff MS, Gladen BC, Brock JW, Grandjean P, Jacobson JL, Korrick SA, Rogan WJ, Weisglas-Kuperus N, Hertz-Picciotto I, Ayotte P, Stewart P, Winneke G, Charles MJ, Jacobson SW, Dewailly E, Boersma ER, Altshul LM, Heinzow B, Pagano JJ, Jensen AA. Comparison of polychlorinated biphenyl levels across studies of human neurodevelopment. Environ Health Perspect. 2003; 111:65-70. [PubMed: 12515680]

Mahaffey KR, Clickner RP, Jeffries RA. Adult women's blood mercury concentrations vary regionally in the United States: association with patterns of fish consumption (NHANES 1999-2004). Environ Health Perspect. 2009; 117:47-53. [PubMed: 19165386]

Maia CSF, Lucena GMS, Corrêa PBF, Serra RB, Matos RWM, Menezes FC, Noro dos Santos S, Batista de Sousa J, Tavares da Costa E, Moraes Ferreira VM. Interference of ethanol and methyl mercury in the developing central nervous system. Neurotoxicology. 2009; 30:23-30. http:// dx.doi.org/10.1016/j.neuro.2008.11.008. [PubMed: 19100288]

Mancinelli R, Vitali M, Ceccanti M. Women, alcohol and the environment: an update and perspectives in neuroscience. Funct Neurol. 2009; 24:77-81. [PubMed: 19775534]

Meacham C, Freudenrich T, Anderson W, Sui L, Lyons-Darden T, Barone S, Gilbert ME, Mundy WR, Shafter TJ. Accumulation of methyl mercury or polychlorinated biphenyls in in vitro models of rat neuronal tissue. Toxicol Appl Pharmacol. 2005; 205:177-187. http://dx.doi.org/10.1016/j.taap. 2004.08.024. [PubMed: 15893545]

Montoya M. Bioethnic conscription: genes, race and Mexicana/o ethnicity in diabetes research. Cult Anthropol. 2007; 22:94-128.

Morello-Frosch R, Shenassa ED. The environmental 'riskscape' and social inequality: implications for explaining maternal and child health disparities. Environ Health Perspect. 2006; 114:1150-1153. http://dx.doi.org/10.1289/ehp.8930. [PubMed: 16882517]

Murray, MP. Econometrics: A Modern Introduction. Pearson Addison-Wesley; Indianapolis, IN: 2005.

Mushak P. Uses and limits of empirical data in measuring and modeling human lead exposure. Environ Health Perspect. 1998; 106:1467-1484. [PubMed: 9860906]

National Research Council. Human Biomonitoring for Environmental Chemicals. The National Academies Press; Washington, DC: 2006.

National Research Council. Phthalates and Cumulative Risk Assessment: The Task Ahead. National Academies Press; Washington, DC: 2008.

Needham LL, Grandjean P, Heinzow B, Jørgensen PJ, Nielsen F, Patterson DG. Partition of environmental chemicals between maternal and fetal blood and tissues. Environ Sci Technol. 2011; 45:1121-1126. [PubMed: 21166449] 
Needham LL, Ozkaynak H, Whyatt RM, Barr DB, Wang RY, Naeher L, Akland G, Bahadori T, Bradman A, Fortmann R, Liu LJS, Morandi M, O'Rourke MK, Thomas K, Quackenboss J, Ryan $\mathrm{PB}$, Zartarian V. Exposure assessment in the National Children's Study: introduction. Environ Health Perspect. 2005; 113:1076-1082. [PubMed: 16079082]

Payne-Sturges D, Gee GC. National environmental health measures for minority and low-income populations: tracking social disparities in environmental health. Environ Res. 2006; 102:154-171. http://dx.doi.org/10.1016/j.envres.2006.05.014. [PubMed: 16875687]

Qin YY, Leung CK, Leung AO, Wu SC, Zheng JS, Wong MH. Persistent organic pollutants and heavy metals in adipose tissues of patients with uterine leiomyomas and the association of these pollutants with seafood diet, BMI and age. Environ Sci Pollut Res Int. 2010; 17:229-240. http:// dx.doi.org/10.1007/s11356-009-0251-0.

Radio N, Freudenrich T, Robinette B, Crofton K, Mundy W. Comparison of PC12 and cerebellar granule cell cultures for evaluating neurite outgrowth using high content analysis. Neurotoxicol Teratol. 2010; 32:25-35. http://dx.doi.org/10.1016/j.ntt.2009.06.003. [PubMed: 19559085]

Roegge CS, Wang VC, Powers BE, Klintsova AY, Villareal S, Greenough WT, Schantz SL. Motor impairment in rats exposed to PCBs and methyl mercury during early development. Toxicol Sci. 2004; 77:315-324. http://dx.doi.org/10.1093/toxsci/kfg252. [PubMed: 14600290]

Shrader-Frechette K. Ideological toxicology: invalid logic, science, ethics about low-dose pollution. Hum Exp Toxicol. 2008; 27:647-657. [PubMed: 19029261]

Schmidt CW. Signs of the times: biomarkers in perspective. Environ Health Perspect. 2006; 114:A701-A705.

Schisterman EF, Whitcomb BW, Buck Louis GM, Louis TA. Lipid adjustment in the analysis of environmental contaminants and human health risks. Environ Health Perspect. 2005; 113 (7):853857. [PubMed: 16002372]

Sexton K, Olden K, Johnson B. "Environmental Justice": the central role of research in establishing a credible scientific foundation for informed decision making. Toxicol Ind Health. 1993; 9:685-727. [PubMed: 8184441]

Sitarek K, Gralewicz S. Early developmental effects of separate or combined perinatal exposure to methyl mercury (MeHg) and 2,2 $2^{\prime}, 4,4^{\prime}, 5,5^{\prime}$-hexachlorobiphenyl (PCB 153) in the rat. Int J Occup Med Environ Health. 2009; 22:89-105. http://dx.doi.org/10.2478/v10001-009-0015-6. [PubMed: 19617190]

Stewart PW, Sargent DM, Reihman J, Gump BB, Lonky E, Darvill T, Hicks H, Pagano J. Response inhibition during differential reinforcement of low rates (DRL) schedules may be sensitive to lowlevel polychlorinated biphenyl, methylmercury and lead exposure in children. Environ Health Perspect. 2006; 114:1923-1929. http://dx.doi.org/10.1289/ehp.9216. [PubMed: 17185286]

Tran NL, Barraj L, Smith K, Javier A, Burke TA. Combining food frequency and survey data to quantify long-term dietary exposure: a methyl mercury case study. Risk Anal. 2004; 24:19-30. [PubMed: 15027997]

US Food and Drug Administration. [accessed 06.04.12] Fish and Fishery Products Hazards and Controls Guidance. 42011. Available from: 〈http://www.fda.gov/downloads/Food/ GuidanceComplianceRegulatoryInformation/GuidanceDocuments/Seafood/UCM251970.pdf $\rangle$

Wigle DT, Arbuckle TE, Walker M, Wade MG, Liu S, Krewski D. Environmental hazards: evidence for effects on child health. J Toxicol Environ Health B Crit Rev. 2007; 10:3-39. http://dx.doi.org/ 10.1080/10937400801921320. [PubMed: 18074303]

Woodruff TJ, Zota AR, Schwartz JM. Environmental chemicals in pregnant women in the United States: NHANES 2003-2004. Environ Health Perspect. 2011; 119:878-885. http://dx.doi.org/ 10.1289/ehp.1002727. [PubMed: 21233055]

\section{Appendix A. Supplementary material}

Supplementary data associated with this article can be found in the online version at http:// dx.doi.org/10.1016/j.envres.2012.10.005. 


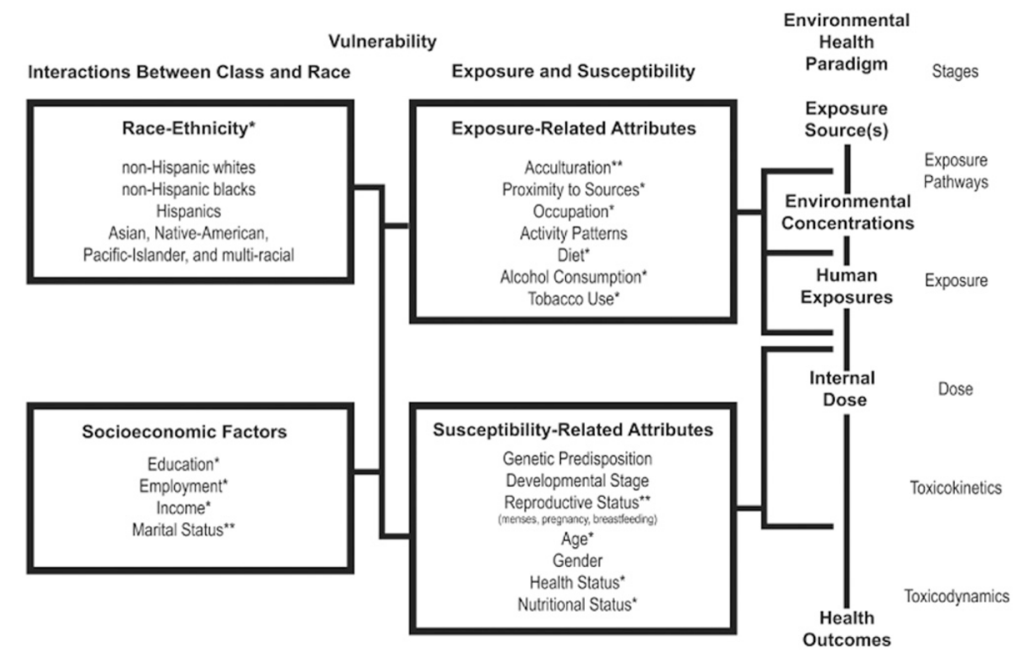

Fig. 1.

Modified environmental health paradigm. Adapted from Sexton et al., 1993, p 714. Bold = original environmental health paradigm; *= original variables; $* *=$ variables added. 


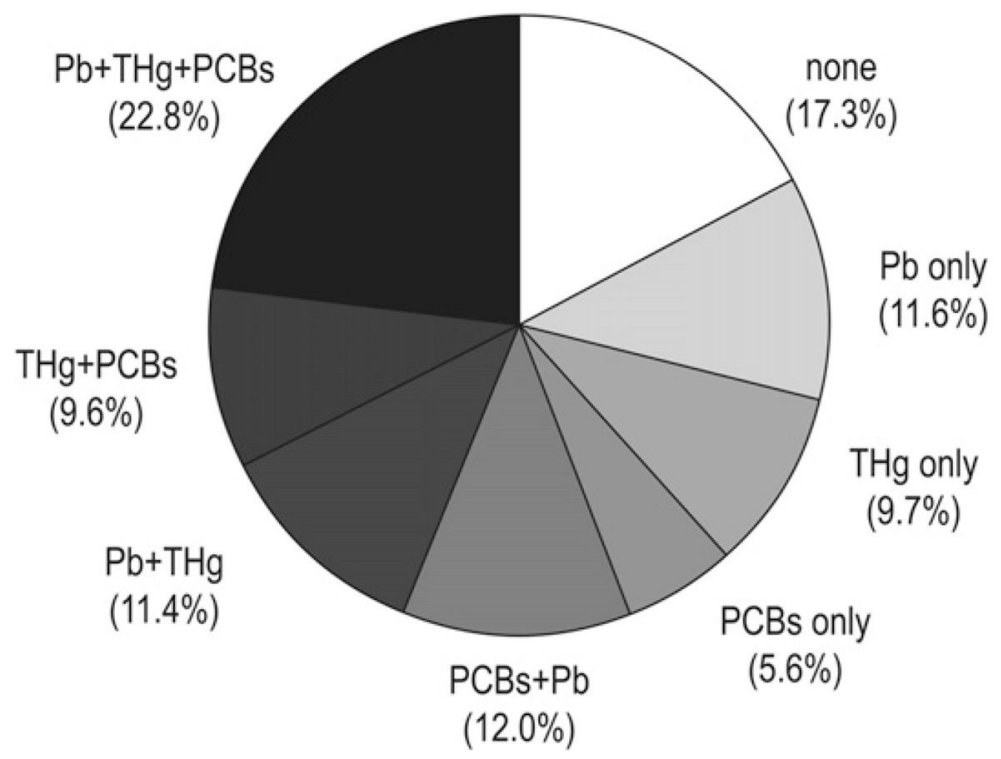

Fig. 2.

Percentage of childbearing-aged women in US burdened by specific xenobiotic combinations at or above the median (NHANES weighted data 1999-2004). 


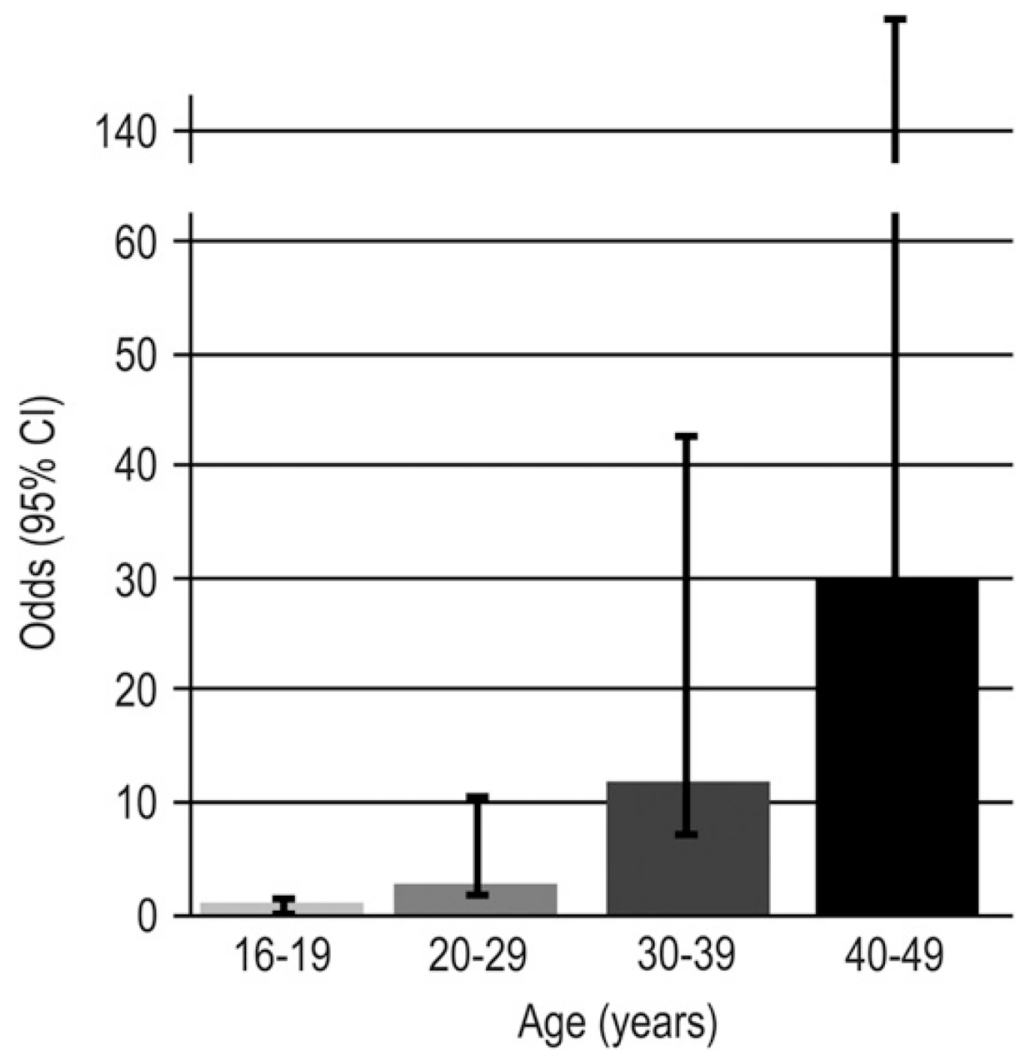

Fig. 3.

Odds of childbearing-aged women in US with two or more xenobiotics at above the median based on age (NHANES weighted data 1999-2004). 

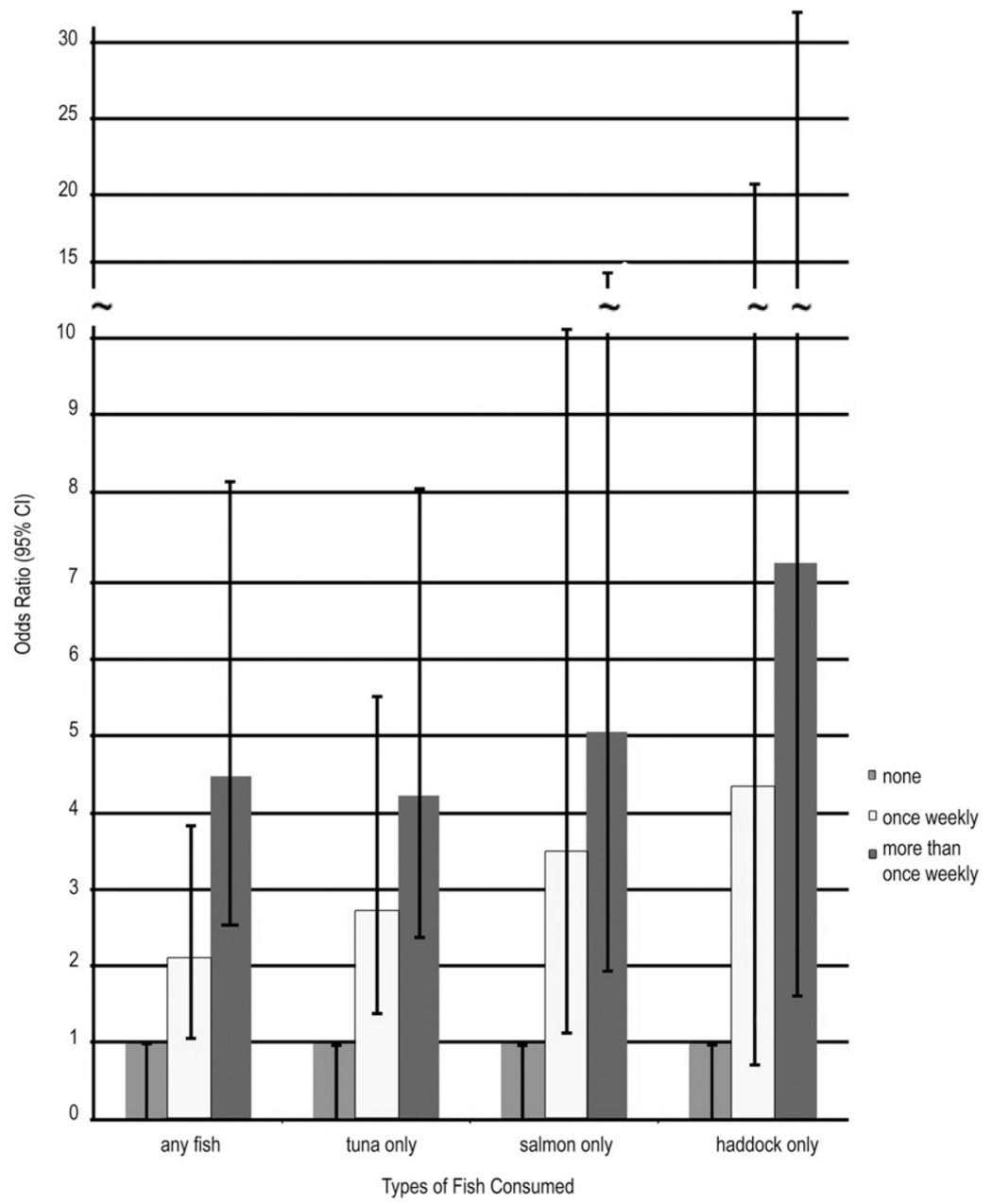

Fig. 4.

Odds of childbearing-aged women having xenobiotic levels at or above the median based on fish consumption (NHANES weighted data 1999-2004). 
Sิ

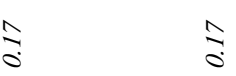

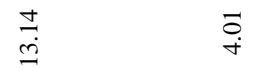

iे

$\ddot{\infty} \quad \stackrel{\infty}{\infty}$

$\stackrel{\infty}{\infty}$

ă
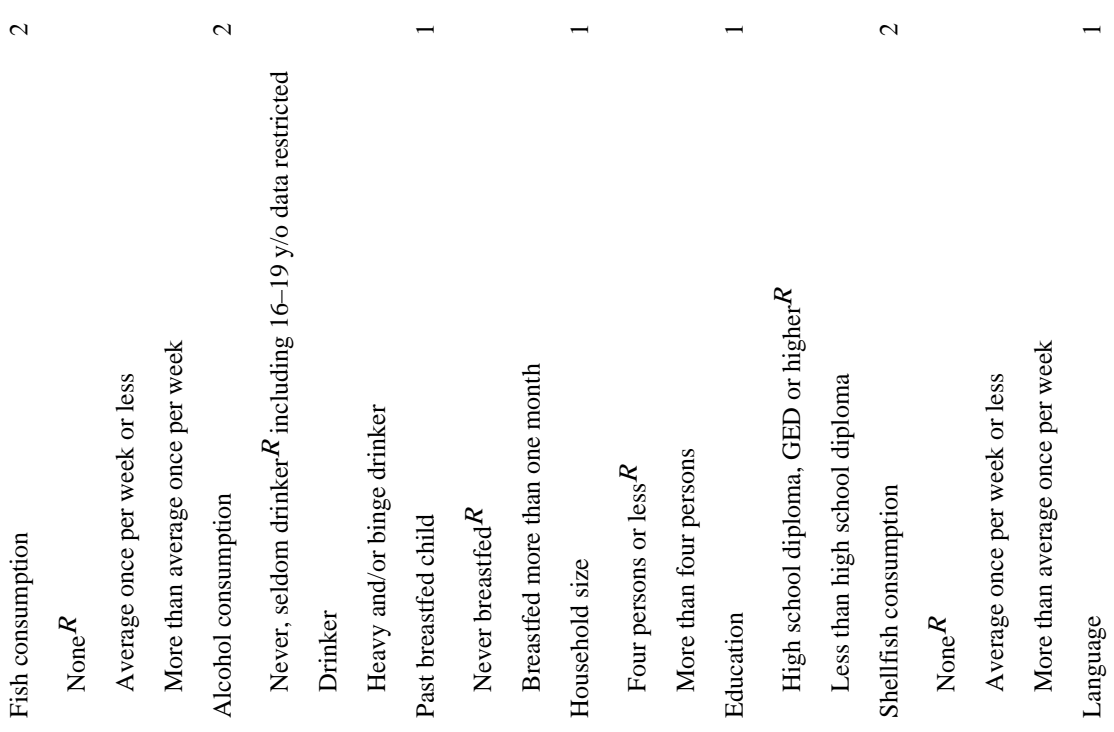


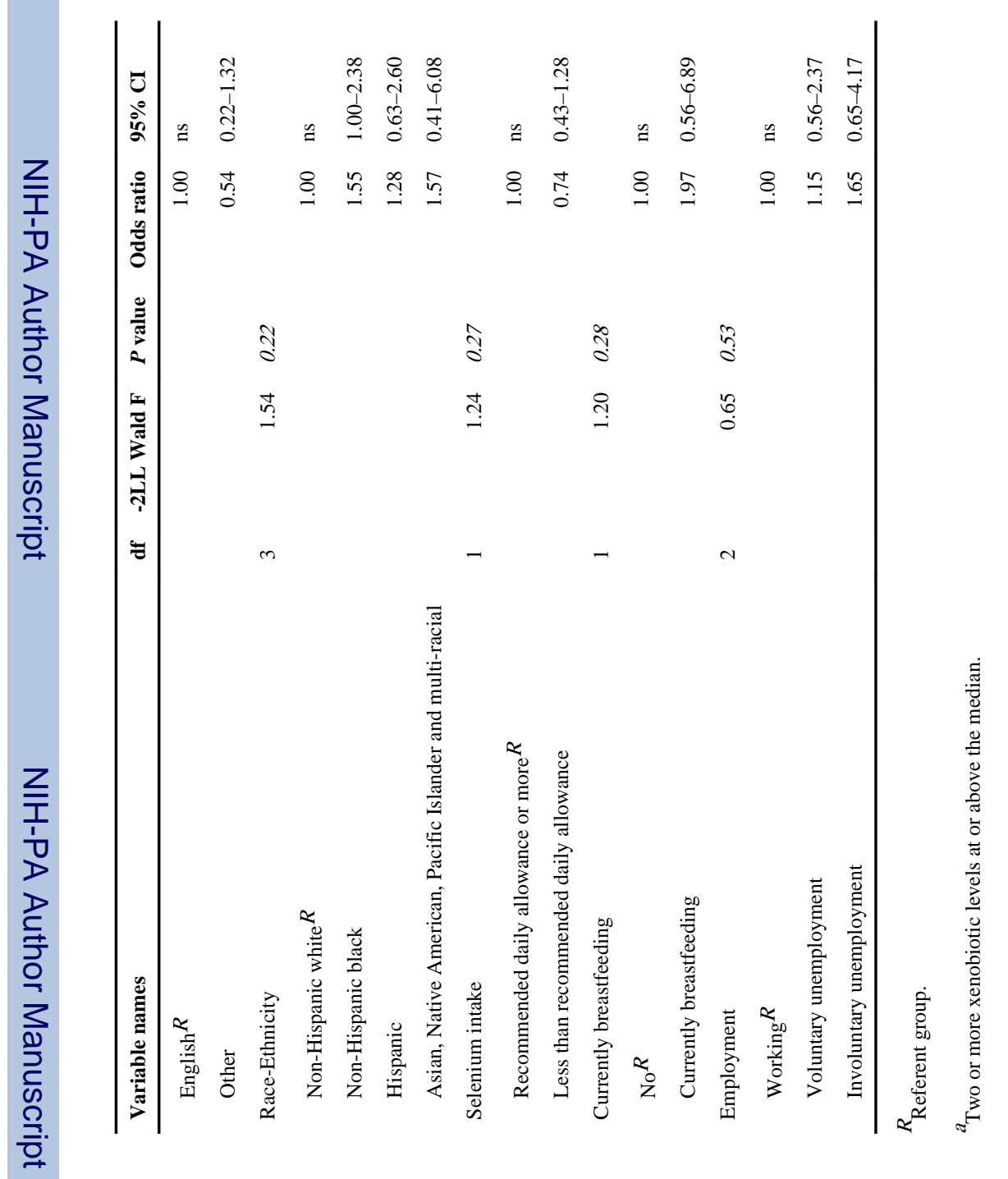

